\title{
Experimental and Density Functional Theory (DFT): a Dual Approach for the Adsorption of Cd (II) Ion from Aqueous Solution by Starch Based Activated Carbon
}

\author{
Saad Melhi ${ }^{1}$, Saeed Ullah Jan ${ }^{2 *}$, Adnan Ali Khan ${ }^{2}$, Khan Badshah ${ }^{2}$, Saeed Ullah ${ }^{2}$, Bushra $^{2}$ and Zeliha Selamoglu ${ }^{3}$ \\ ${ }^{1}$ Department of Chemistry, College of Science, University of Bisha, Bisha, 61922, \\ ${ }^{2}$ Department of Chemistry, Chakdara Lower Dir, 18800, University of Malakand, Pakistan \\ ${ }^{3}$ Department of Medical Biology, Faculty of Medicine, Niğde, Turkey \\ *Correspondence: saeedsimaab@gmail.com
}

\begin{abstract}
:
Cadmium (II) contamination in the environment is an emerging problem due to its acute toxicity and mobility, so it is very urgent to remove this specie from industrial wastewater before it is discharged into the environment. Thus, a starch-based activated carbon (AC) with a specific surface area of $1600 \mathrm{~m}^{2} \mathrm{~g}^{-1}$ is used as an adsorbent for the capturing of toxic Cadmium (II) ion from synthetic solution. The sorbent is characterized by BET, SEM, TEM, XRD, FT-IR, TGA, and zeta potential. The maximum uptake $\left(284 \mathrm{mg} \mathrm{g}^{-1}\right)$ of Cadmium (II) ion is obtained at $\mathrm{pH} 6$. The thermodynamics parameters like $\Delta G, \Delta H, \Delta S$ are found to be $-17.42 \mathrm{kJmol}^{-1}, 6.49 \mathrm{~kJ} \mathrm{~mol}^{-1}$, and 55.66 $\mathrm{Jmol}^{-1} \mathrm{~K}^{-1}$ respectively, revealing that the adsorption mechanism is endothermic, spontaneous, and feasible. The experimental data follows the D-R and Langmuir models well. The mass transfer is controlled by pseudo $2^{\text {nd }}$ order kinetics. Furthermore, the density functional theory simulations demonstrates that the activated carbon strongly interacted with the Cd (II) ion through its various active sites. The adsorption energy noted for all interactive sites is highly negative $(-0.45 \mathrm{eV}$ to $-10.03 \mathrm{eV})$, shows that the adsorption process is spontaneous and stable which are in agreement with the experimental thermodynamics analysis.
\end{abstract}

Keywords: Adsorption; DFT; Cadmium (II) ion; Activated carbon; Kinetics; Thermodynamics; 


\section{Introduction}

Due to the rapid industrialization and urbanization the heavy metals concentration has increased enormously in water reservoirs. The rate of depletion of water reservoirs is alarming and is a serious environmental problem[1,2]. The clean water vitality cannot be compromised at any case. The large number of pollutants have been identified from industrial and domestic sources and are included of antibiotics, dyes phenols, insecticides and heavy metals constituents $[3,4]$. Due to the non- degradable and accumulative nature, heavy metals are extremely harmful for living organisms. Among heavy metals the non-nutritive cadmium (II) metal is classified as human teratogen, carcinogen, the most dangerous and priority water pollutant with biological half-life about 10-30 years [5].

The main sources of Cd(II) ion contamination are industrial wastewater, combustion of oil and coal and wastes incineration. The $\mathrm{Cd}(\mathrm{II})$ is extensively used in different industrial processes e.g., as a coloring pigment, anticorrosive agent, fabrication of batteries, in a nuclear power plants as an absorber of neutrons. It is been estimated that about 7000 tones /annum has been released on global level [6]. According to the world health organization (WHO), the permissible level of $\mathrm{Cd}$ (II) is less than $0.003 \mathrm{mg} \mathrm{dm}^{-3}$ for drinking water [6]. The Cd(II) has noxious effect on lungs, liver and kidney even in a very low concentration $[7,8]$. The inhaling of $\mathrm{Cd}$ (II) contaminated air can cause shortness of breath, damage of mucous membranes and lung edema. The intake of food contaminated with $\mathrm{Cd}(\mathrm{II})$ can cause diarrhoea and severe vomiting. Similarly, it can cause bone damage, infertility, prostate cancer and tumor [9,10]. So, it is pertinent for human health and environmental safety to ascertain the concentration of $\mathrm{Cd}(\mathrm{II})$ on regular basis and develop techniques for the capturing of $\mathrm{Cd}(\mathrm{II})$ ion, before it is discharged into water bodies.

Several techniques like reverse osmosis, ion exchange, chemical precipitation, electrolytic extraction, redox method, and electrodialysis have been designed and applied for the scavenging of heavy metals. However, these methods have their limitations e.g., long processing time, high energy consumption, and poor sequestration of heavy metals [11].

Chemical precipitation is one of the most widely used for heavy metal removal from inorganic effluent in industry due to its simple operation . These conventional chemical precipitation processes produce insoluble precipitates of heavy metals as hydroxide, sulfide, carbonate and phosphate [12].

Ion Exchange Ion exchange can attract soluble ions from the liquid phase to the solid phase, which is the most widely used method in water treatment industry. As a cost-effective method, ion exchange process normally involves low-cost materials and convenient operations, and it has been proved to be very effective for removing heavy metals from aqueous solutions, particular for treating water with low concentration of heavy metals[13].

The adsorption technique is efficient as it is simple in operation, cost-effective, and environmentally friendly [1]. A variety of adsorbents like silica gel $[14,15]$, clay [16,17] and bio sorbents [18] have already been reported for the sequestration of heavy metals from wastewater. The theoretical analysis is a complementary tool to know the mechanism of the absorption process [19-21]. The efficiency of ACs as adsorbents for diverse types of pollutants is well reported [22]. It is well known that activated carbon has been found much efficient for removing organic compounds than metals and other inorganic pollutants. Efforts are ongoing to 
substantially improve the potential of carbon surface by using different chemicals or suitable treatment methods which will enable AC to enhance its potential for the removal of specific contaminants from aqueous phase. The physical and chemical structure of carbon could be changed by various methods, i.e. activation conditions (different agents, temperature and time of the process), precursor, additives, etc.

Starch based activated carbon was prepared and characterized to remove Cd(II) ion from spiked water. For the determination of the adsorption mechanism the data were subjected to different adsorption models. The sorption obeys $2^{\text {nd }}$ order kinetics, Freundlich and Langmuir isotherms and was more favorable at $\mathrm{pH}$ 6. For the determination of thermodynamic parameters of the adsorption mechanism, the temperature study was carried out, which shows that the adsorption was spontaneous, feasible, and of endothermic nature. The DFT supported the experimental findings.

\section{Experimental Section}

\subsection{Materials}

All the chemicals like $\mathrm{CdCl}_{2}$, dithizone, $\mathrm{NaOH}, \mathrm{HCl}, \mathrm{KOH}, \mathrm{CH}_{3} \mathrm{COOH}, \mathrm{CH}_{3} \mathrm{COONa}, \mathrm{H}_{3} \mathrm{BO}_{3}$, and $\mathrm{NaOH}$ of analytical grade were supplied by Sigma Aldrich Pakistan (Pvt.) Ltd. and were used without any further purification. The solutions of buffer 1-7 with the ionic strength of $10 \mathrm{mmol}$ were prepared by taking the calculated amount of $\mathrm{KCl}$ and $\mathrm{HCl}$ for buffer $1-2, \mathrm{CH}_{3} \mathrm{COOH}$, and $\mathrm{CH}_{3} \mathrm{COONa}$ for buffer 3-6, and $\mathrm{NaOH}$ and $\mathrm{H}_{3} \mathrm{BO}_{3}$ for buffer $7 . \mathrm{CdCl}_{2}$ was mixed with dithizone in $2 \mathrm{M} \mathrm{NaOH}$ to get orange coloured Cd-dithizone complex (Figure 1) and its absorbance was studied at $549 \mathrm{~nm}$ wavelength as compared to the standard [23].

The concentration of Cadmium (II) ions was determined from its complex with dithizone in the presence of non-ionic surfactant e.g., CTAB. The molar absorptivity of complex becomes almost double as compare to the standard method and a very small amount of $\mathrm{Cd}^{+2}$ can be determined spectrometrically at wavelength of $549 \mathrm{~nm}$. The increase in the molar absorptivity and rate constant are due to the micelle, which favours the formation of a Cd (II) ion and dithizone complex.

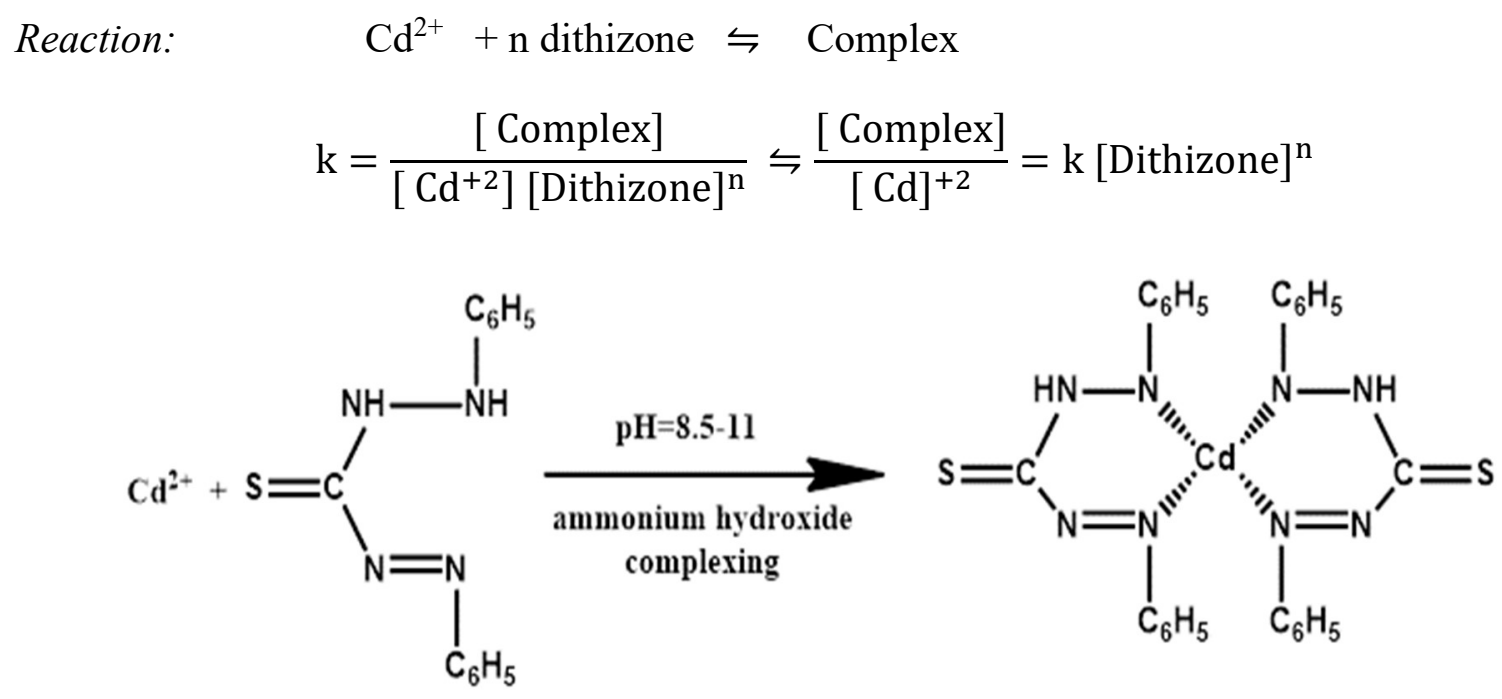

Figure 1. Cadmium Dithizone Complex.

\subsection{Synthesis of Adsorbent}


The starch sample was sieved by 300 mesh size and mixed with potassium hydroxide in a $1: 4$ weight ratio and activated at $850^{\circ} \mathrm{C}$ for 90 minutes with argon at $3^{\circ} \mathrm{C} /$ minute rise. The obtained product was thoroughly washed again and again with $5 \mathrm{wt}$. $\% \mathrm{HCl}$ followed by washing with double distilled water until the product was neutralized and dried at $120^{\circ} \mathrm{C}$ overnight. The product thus obtained was named starch based activated carbon (AC) and characterized by BET, SEM, TEM, XRD, FT-IR, TGA, and zeta potential [24].

\subsection{Adsorption experiment}

Glass culture tubes with a given amount of adsorbent and a specific volume of sorbate with a known concentration were used in the batch mode experiments at room temperature or specified otherwise. The culture tubes were shaken on a wrist action shaker (Model Burrell 75, Burrell Scientific, USA). After shaking the concentration of Cd(II) was recorded by using a double beam UV-Visible spectrophotometer (Labmed. Inc UVD 2960). The adsorbed amount of $\mathrm{Cd}(\mathrm{II})$ and the distribution coefficient $\left(\mathrm{K}_{\mathrm{d}}\right)$ were determined through the following equations.

$$
\begin{aligned}
& \% \text { Adsorption }=\frac{A \mathrm{i}-A_{f}}{A i} \times \text { vol (1) } \\
& K_{d}=\frac{\text { Amount of } \text { Cd }(\text { II }) \text { ion adsorbed onto sorbent }}{\text { Amount of } \boldsymbol{C d}(\text { II }) \text { ion remaining in the solution }} \times \frac{\boldsymbol{V}}{W}
\end{aligned}
$$

where $A_{i}$ is the initial $\mathrm{Cd}(\mathrm{II})$ concentration, $\mathrm{A}_{\mathrm{f}}$ is the equilibrium concentration, $\mathrm{W}$ represents the weight of sorbent and $\mathrm{V}$ is the volume of $\mathrm{Cd}(\mathrm{II})$ solution.

All the experiments were carried out in triplicate at room temperature or described otherwise. The linear regression of the data was carried out and was in the range of 1-0.997 for all analyses.

\section{Results and discussion}

\subsection{Material Characterization}

The activated carbon derived from starch was used for the adsorption of $\mathrm{Cd}(\mathrm{II})$ ion from industrial wastewater. The material was characterized through the following techniques. 3.1.1. SEM and TEM analysis

The SEM images of the AC derived from starch at different resolutions illustrate the sheet type morphology that ranges from nanometer to several micrometers (Figure 2 a and b), whereas the TEM images at low and high magnification further confirm the multilayer nature of the individual sheet for the obtained activated carbon (Figure $\mathbf{2} \mathbf{c}$ and d) [25]. 

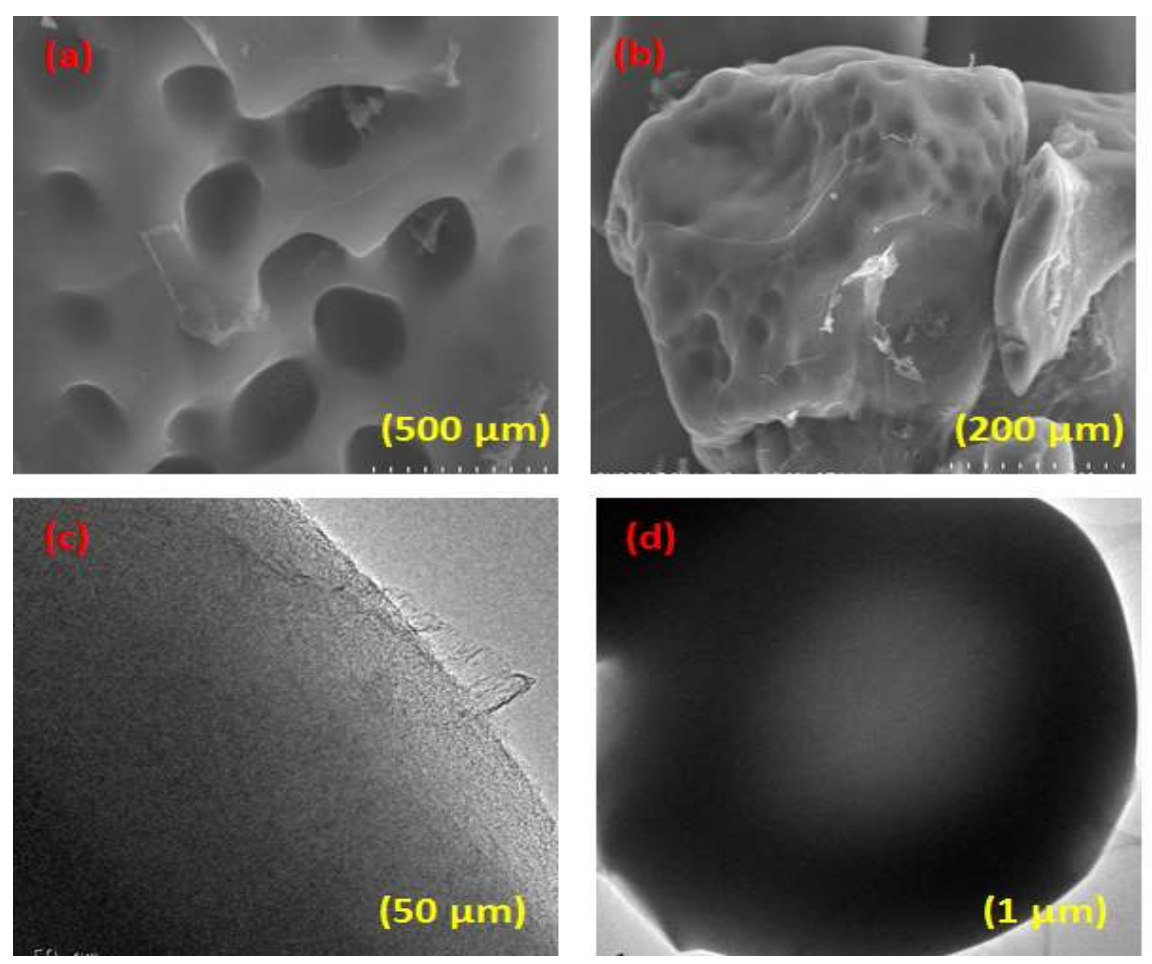

Figure 2. (a, b) SEM images of the starch-based AC and (c, d) TEM images of starchbased AC.

\subsubsection{AFM analysis}

AFM technique was performed further to investigate the average and maximum height of the AC Figure 3 (a-d) shows the 2-dimensional (2D) and 3-dimensional (3D) patterns of starch-based AC with particle height that varied from 5 to $50 \mathrm{~nm}$ [26]. Thus, through the AFM technique, we could guess the maximum height $(50 \mathrm{~nm})$ of the multilayer AC sheets, which make it an attractive choice for toxic $\mathrm{Cd}(\mathrm{II})$ ion adsorption [23]. 
(a)

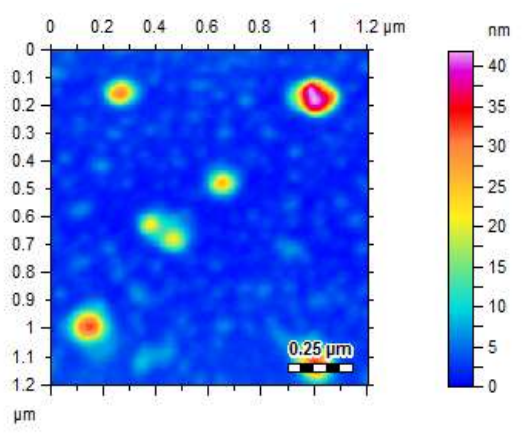

(c)

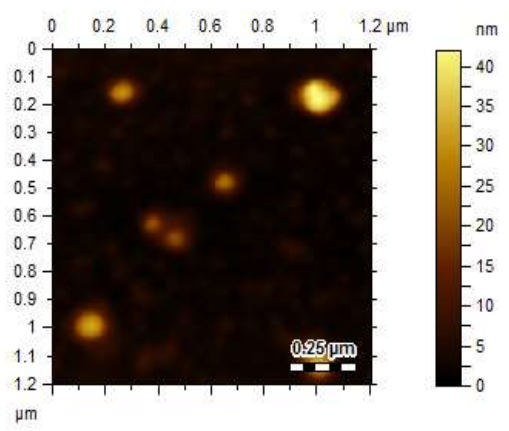

(b)

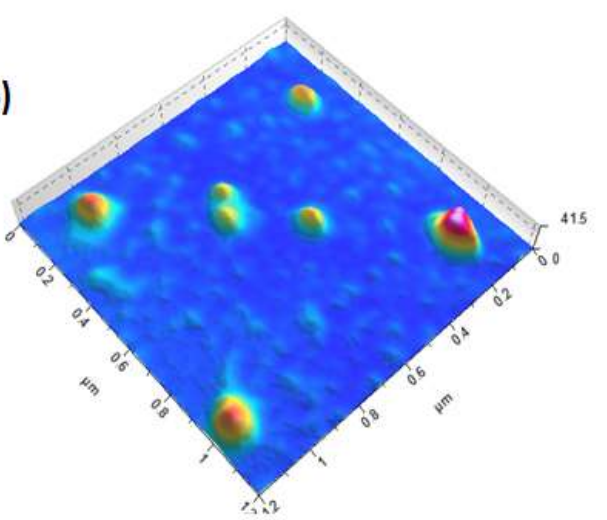

(d)

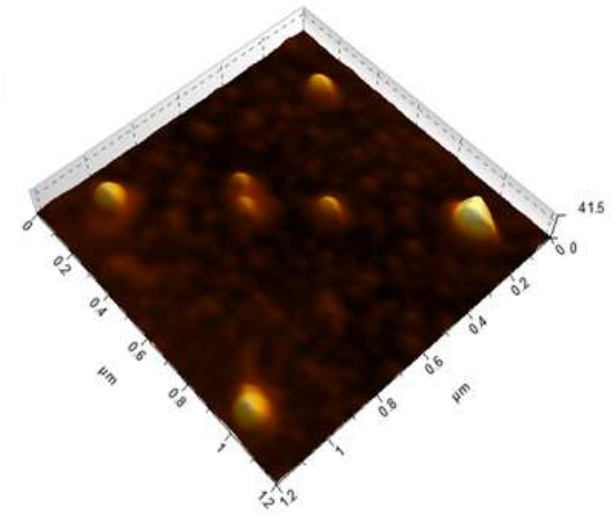

Figure 3. AFM (a) 2D and (b) 3D images of the Starch-based AC.

\subsubsection{FT-IR analysis}

FTIR analysis is used to confirm different groups on the surface of AC (Figure 4). The broader peak at $3480 \mathrm{~cm}^{-1}$ in corresponds to the hydroxyl group [27]. The absorption peaks at 2920 is due to $-\mathrm{CH}_{3}$ and peak at $1720 \mathrm{~cm}^{-1}$ is due to $-\mathrm{C}=\mathrm{O}$ vibration [28]. The peaks on 1550 and $1115 \mathrm{~cm}^{-1}$ representing $-\mathrm{NO}_{2}$ and $-\mathrm{SO}_{3} \mathrm{H}$ groups respectively [29]. The spectra indicates that starch-based $\mathrm{AC}$ contains aromatic rings [30].

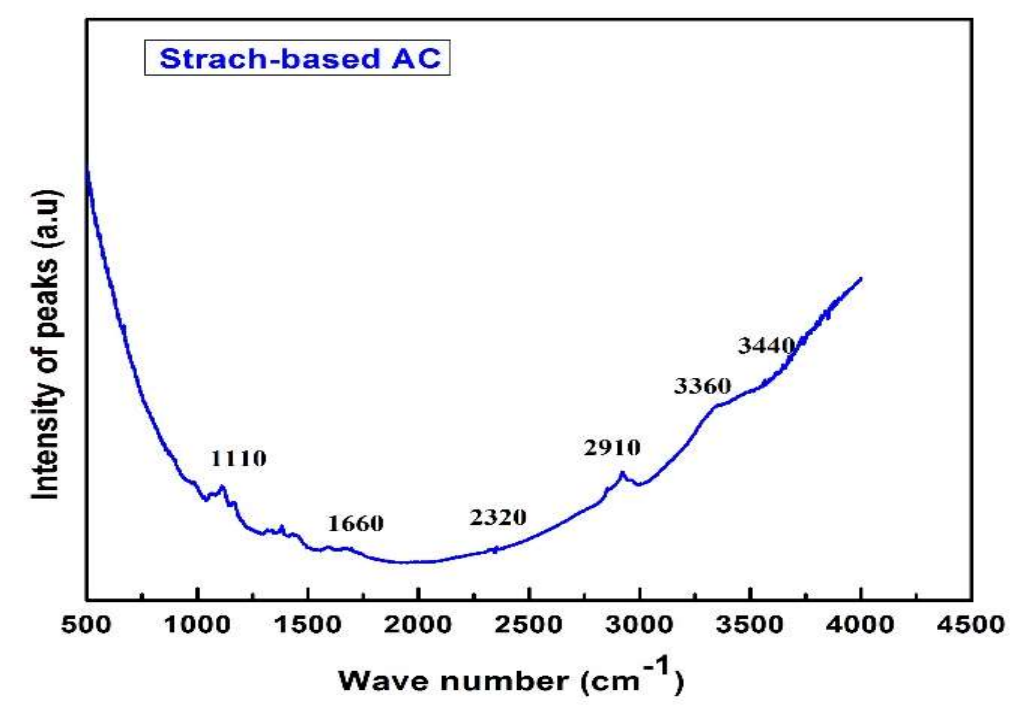


Figure 4. FTIR spectra of starch-based AC.

\subsubsection{XRD analysis}

The structure and crystallinity of activated carbon was investigated by using XRD technique Figure 5 represents the XRD patterns of virgin starch-based AC. In the XRD patterns, the peaks at $2 \theta=25^{\circ}$ and $2 \theta=43.460^{\circ}$ originates from its graphite-like nature and can be assigned to the (002) and (100) plane of graphitic carbon, respectively [31,32].

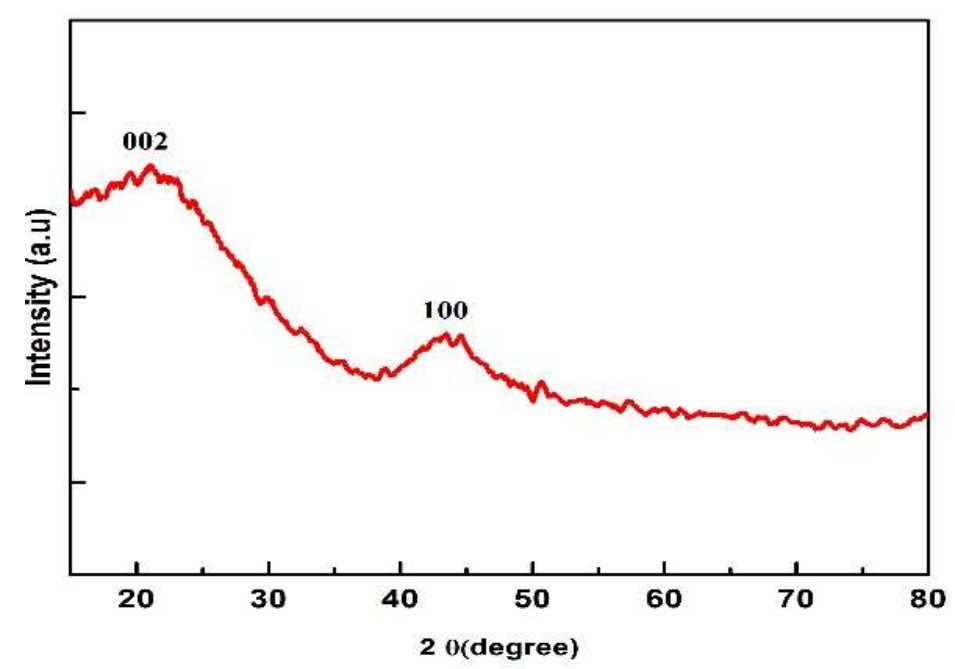

Figure 5. XRD pattern of starch-based AC

\subsubsection{TGA Study}

The thermal stability of the starch-based AC was studied at temperature up to $1000^{\circ} \mathrm{C}$, from TGA analysis it can be concluded that the starch-based AC was stable at a very high temperature (Figure 6). The starch-based $\mathrm{AC}$ converted into $\mathrm{CO}$ and $\mathrm{CO}_{2}$ [33] and some other compounds at various temperatures [34]. At the end only $11 \%$ loss was observed from the total mass of starch-based AC.

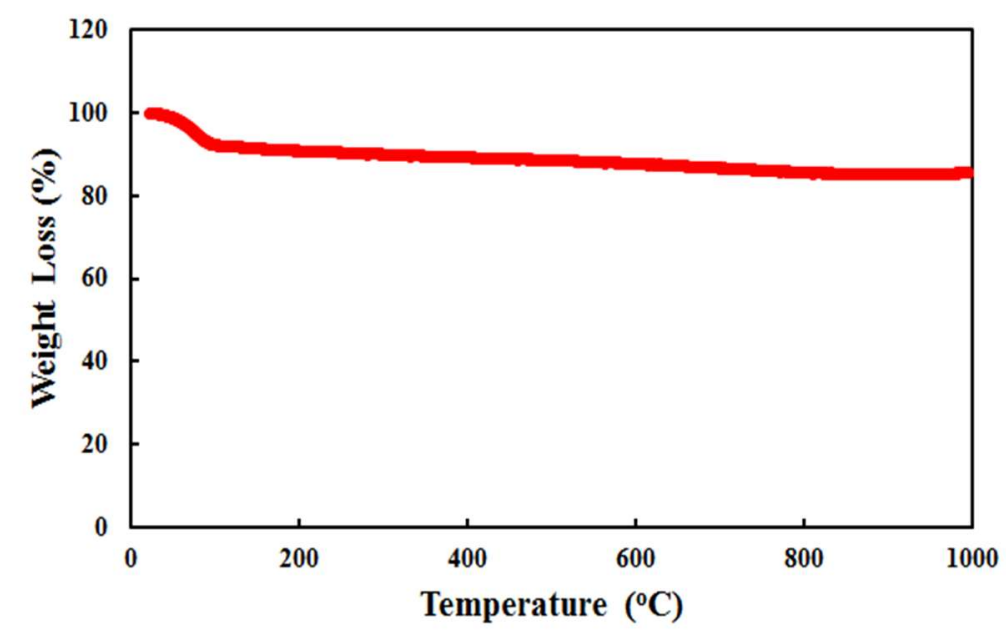


Figure 6. TGA plot of the Starch-based AC.

\subsubsection{Zeta potential and zeta sizer analysis}

The particle size distribution is a useful parameter to elucidate the arrangement of particle size in the adsorbents while its zeta potential determines its surface charge required for dispersion. Figure 7 shows the size distribution and zeta potential plots of the $\mathrm{AC}$, which reveals that the average particle size was $575 \mathrm{~nm}$ and polydispersity index (PDI) of 0.635 , representing sufficient variation in sizes. Its surface charge was $-16.9 \mathrm{mV}$, which is sufficient to remain suspended [35].
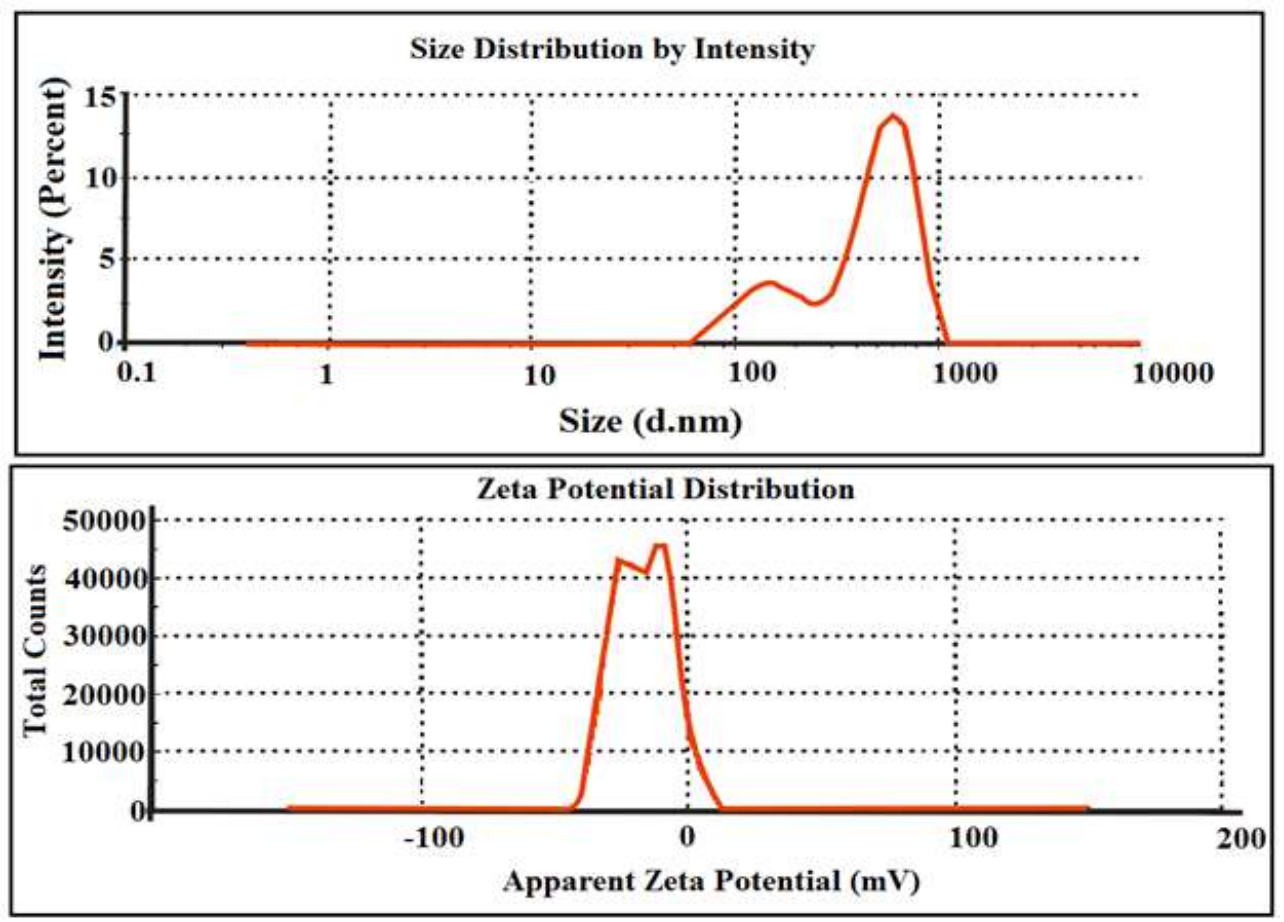

Figure 7. Zeta sizer and zeta potential of the starch-based AC.

\subsubsection{BET and BJH analysis}

The surface area was found to be $1600 \mathrm{~m}^{2} \mathrm{~g}^{-1}$ of starch-derived AC as determined from BET isotherm, with porous structure (Figure 8). The BJH analysis shows that AC has microspores and mesopores on its surface (inset of Fig. 8a). While the BET isotherm Figure $8 \mathbf{b}$ shows the $\mathrm{Cd}$ (II) ions loaded $\mathrm{AC}^{\text {, s }}$ surface area, which remained only $13.35 \mathrm{~m}^{2} \mathrm{~g}^{-1}$, reflecting that most of the surface has been covered by the metal. 
(a)

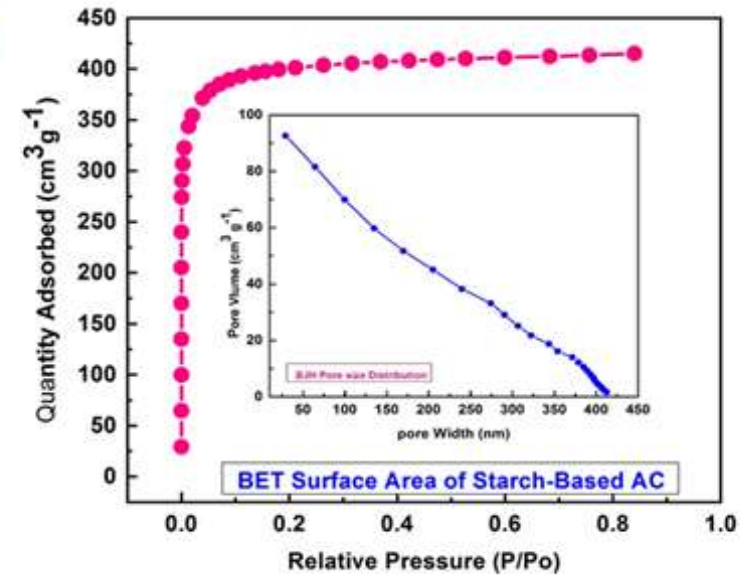

(b)

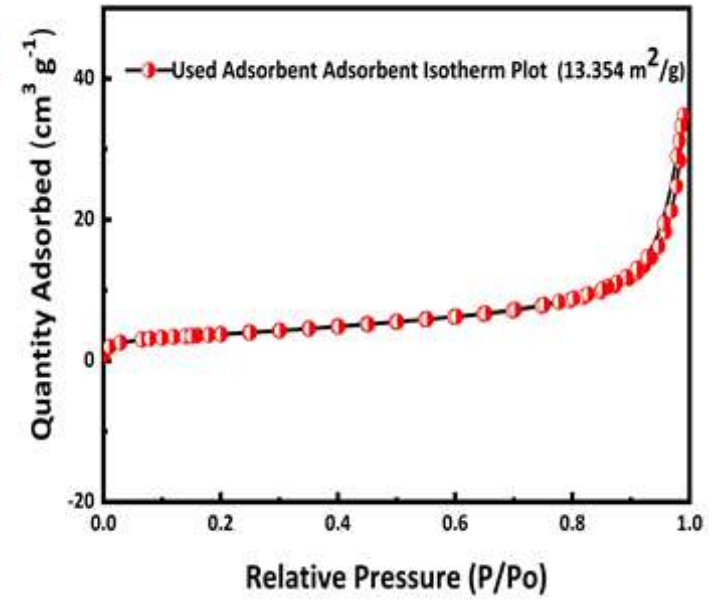

Figure 8. (a) Nitrogen sorption isotherm of Starch-based $\mathrm{AC}$ at $77.5 \mathrm{~K}$ with inset of $\mathrm{BJH}$ pore size distribution and (b) BET isotherm of the $\mathrm{Cd}(\mathrm{II})$ ion loaded $\mathrm{AC}$

\subsection{Adsorption experiments}

\subsubsection{Effect of $\mathrm{pH}$ on sorption}

The sorption capacity is greatly influenced by the medium [2]. The effect of $\mathrm{pH}$ on the adsorption of $\mathrm{Cd}$ (II) was investigated at $\mathrm{pH} 1.0$-9.0. The concentration of sorbate of $100 \mathrm{mg} \mathrm{L}^{-1}$, sorbent amount of $30 \mathrm{mg}$, and shaking time of 120 minutes were chosen arbitrarily. The equilibrium uptake of $\mathrm{Cd}$ (II) increased notably up to $\mathrm{pH} 6$ and then decreased continuously (Figure 9a). The maximum uptake $(98.58 \%$ ) was observed at $\mathrm{pH} 6$ and was selected for further experiments. At acidic $\mathrm{pH}$, the electrostatic repulsion is created between protonated surface of $\mathrm{AC}$ and $\mathrm{Cd}(\mathrm{II})$ metal ion. These observations have also been reported by other researchers [5,36]. Beyond $\mathrm{pH} 6$ the adsorption capacity has decreased due the formation of $\mathrm{Cd}(\mathrm{OH})_{2}$ (cadmium hydroxide) [37].

Based on equilibrium constants, a speciation diagram was constructed and is depicted in Figure 9e. The diagram shows that at $\mathrm{pH}$ below 6 , the $\mathrm{Cd}^{2+}$ ion predominates and at $\mathrm{pH}$ values just below 7, cadmium begins to precipitate out as $\mathrm{Cd}(\mathrm{OH})_{2}$. At $\mathrm{pH}$ of 6 the species distribution is approximately $90 \% \mathrm{Cd}^{2+}$ and $10 \% \mathrm{Cd}(\mathrm{OH})^{+}$. This means that all the species occurring at $\mathrm{pH}$ values of 6 and below carry a positive charge either as $\mathrm{Cd}^{2+}$ or $\mathrm{Cd}(\mathrm{OH})^{+}$. Depending on the $\mathrm{pH}$ of the solution, the $\mathrm{Cd}^{2+}$ in aqueous solution can form various species or hydro complexes.[38]

$$
\begin{aligned}
& \mathrm{Cd}^{+2}+\mathrm{H}_{2} \mathrm{O} \rightleftharpoons \mathrm{Cd}(\mathrm{OH})^{+}+\mathrm{H}^{+} \quad \mathrm{pK}_{1}=9.0 \\
& \mathrm{Cd}^{+2}+2 \mathrm{H}_{2} \mathrm{O} \rightleftharpoons \mathrm{Cd}(\mathrm{OH})_{2}+2 \mathrm{H}^{+} \quad \mathrm{pK}_{2}=19.09 \\
& \mathrm{Cd}^{+2}+3 \mathrm{H}_{2} \mathrm{O} \rightleftharpoons \mathrm{Cd}(\mathrm{OH})_{3}+3 \mathrm{H}^{+} \mathrm{pK}_{3}=30.2 \\
& \mathrm{Cd}^{+2}+2 \mathrm{H}_{2} \mathrm{O} \rightleftharpoons \mathrm{Cd}(\mathrm{OH})_{\mathrm{S}^{+}}+2 \mathrm{H}^{+} \mathrm{pK}_{\mathrm{S}}=30.2
\end{aligned}
$$




\subsubsection{Effect of $\mathrm{Cd}(\mathrm{II})$ ion solution concentration}

The effect of Cd(II) ions solution concentration was studied at 20-220 mg/L ( Figure 3.63b). The rate of removal of adsobate was maximum at $80 \mathrm{mg} / \mathrm{L}$ and then it remained constant $[39,40]$, thus $80 \mathrm{mg} / \mathrm{L}$ was taken as standard for further experiments.

The Langmuir equation was used in the following form:

$$
\frac{C_{e}}{q_{e}}=\frac{C_{e}}{Q_{\max }}+\frac{1}{K_{L} Q_{\max }}
$$

where $\mathrm{Q}_{\max }$ is the amount adsorbed, $\mathrm{K}_{\mathrm{L}}, \mathrm{q}_{\mathrm{e}}$ and $\mathrm{C}_{\mathrm{e}}$ were calculated from slope and intercept of the graph, (Figure 9d) and their magnitudes are listed in Table 1. The adsorbate affinity $\left(\mathrm{R}_{\mathrm{L}}\right)$ is represented as below:

$$
R_{L}=\frac{1}{1+K_{L} C_{e}}
$$

The $\mathrm{R}_{\mathrm{L}}$ (0.0072) indicating favourable adsorption [41]..

The Freundlich equation was used in the following form [42].

$$
\log q_{e}=\log K_{F}+\frac{1}{n} \log C_{e}
$$

where the adsorption capacity $\left(\mathrm{K}_{\mathrm{F}}\right.$ mmol.g $\left.\mathrm{g}^{-1}\right)$ and $1 / \mathrm{n}$ represented the surface heterogeneity and can be calculated from the slope and intercept of the graph (Figure 9c). The Freundlich parameters are tabulated in Table $1[43,44]$.

Table 1. Langmuir and Freundlich parameters along with correlation coefficients for the adsorption of $\mathrm{Cd}$ (II) ion onto $\mathrm{AC}$ at $\mathrm{pH} 6$.

\begin{tabular}{cccccccc}
\hline & \multicolumn{3}{c}{ Langmuir parameters } & \multicolumn{3}{c}{ Freundlich parameters } \\
Temperature (K) & $\mathbf{Q}$ max. (mg/g) & $\mathbf{K}_{\mathbf{L}}$ & $\mathbf{\mathbf { R } _ { \mathbf { L } }}$ & $\mathbf{R}^{\mathbf{2}}$ & $\mathbf{K}_{\mathbf{F}}$ & $\mathbf{1} / \mathbf{n}$ & $\mathbf{R}^{\mathbf{2}}$ \\
283 & 270.0 & 26.74 & 0.0072 & 0.999 & 1.002 & 0.0025 & 0.994 \\
293 & 281.0 & 25.57 & 0.0011 & 0.997 & 1.321 & 0.0991 & 0.984 \\
& & & & & & & \\
303 & 284.11 & 25.24 & 0.0010 & 0.998 & 1.3321 & 0.0031 & 0.988 \\
\hline
\end{tabular}


(a)

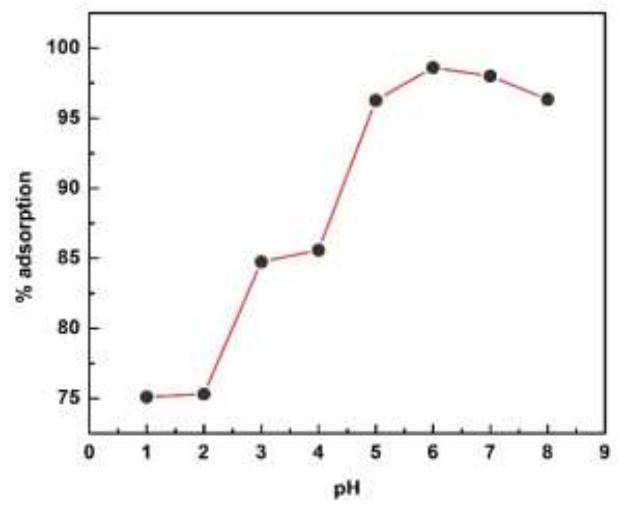

(c)

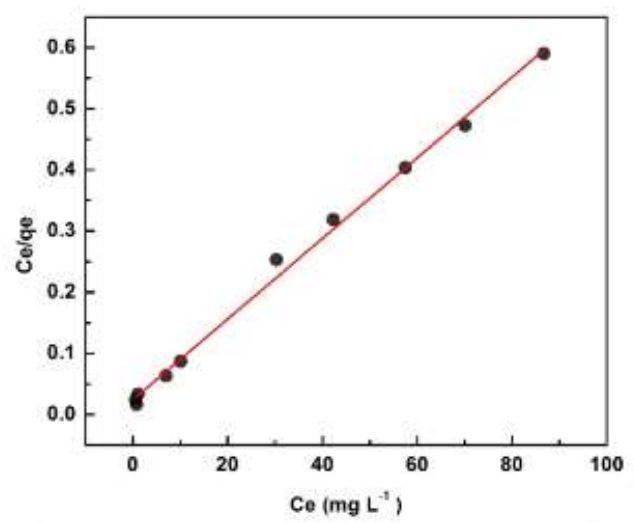

(b)

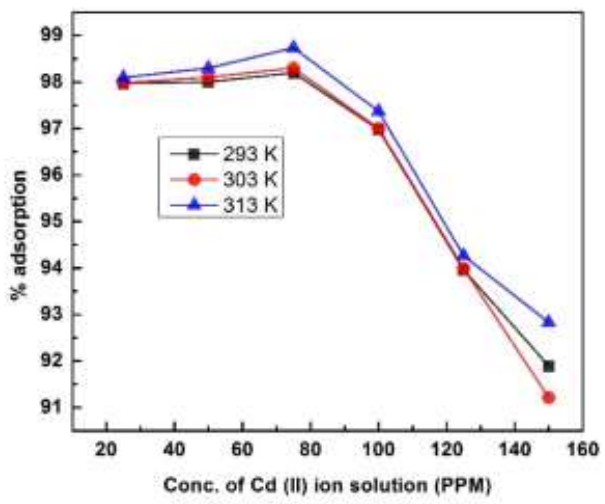

(d)

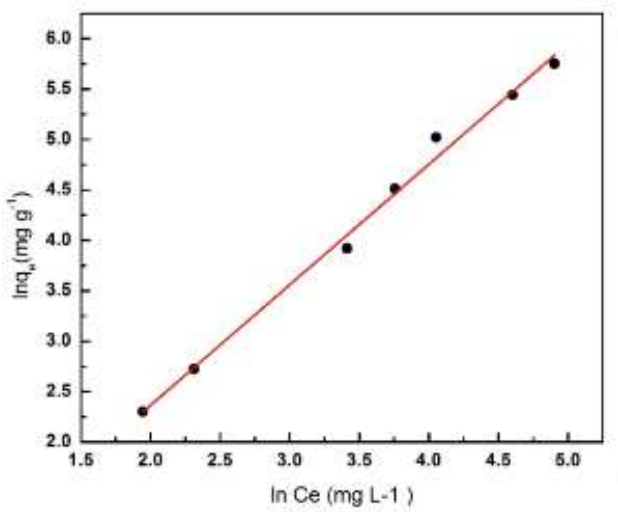

(e)

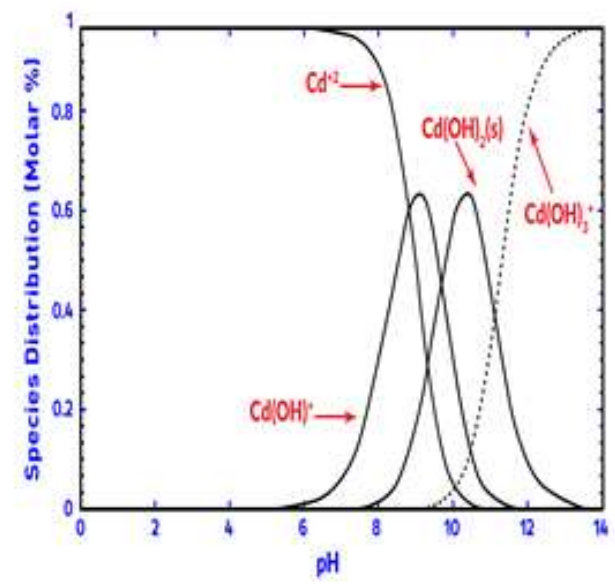

Figure 9. (a) Effect of pH, (2) effect of concentration, (c) Freundlich, (d) Langmuir isotherms and (e) Speciation diagram for cadmium complexes present in aqueous solutions. 


\subsubsection{Influence of the $\mathrm{AC}$ dose}

The influence of the dose of the AC on the adsorption of Cd (II) ion was teste at AC dose ranges 0.01-0.035 $\mathrm{g}$ Figure 10a. The rate of adsorption increased at the AC dose up to 0.025 $\mathrm{g}$ and then it remained constant. Thus, $0.025 \mathrm{~g}$ was taken as standard for further experiments.

\subsubsection{Influence of shaking time}

The influence of shaking time on $\mathrm{Cd}(\mathrm{II})$ ion removal was investigated between $0-50$ minutes. The equilibrium was attained within 40 minutes and wa selected for further investigations (Figure 10b). The adsorption rate of Cd (II) ion was high initially, as abundant vacant sites were available and after that, the movement of the ions was intraparticle which was relatively a slow process

The mass transfer during the process in the rate determining step can be determined by using kinetic models $[2,45,46]$. The pseudo $2^{\text {nd }}$ order equation applied in the following linear form was the best fitted.

$$
\frac{t}{q_{t}}=\frac{1}{k_{2} q_{e}^{2}}+\frac{1}{q_{e}} t
$$

where $k_{2}$ rate constant and qe can be determined from the slope Fig. 10c and their magnitudes are calculated and are listed in Table 2. The experimental and theoretical values of qe are in close agreement with each other, indicating the applicability of the model.

The Reichenberg equation were used in the following form in order to further explore the mechanism [47].

$$
\begin{aligned}
& F=\left(\frac{1-6}{\pi^{2}}\right) e^{-B T} \\
& B_{T}=-0.4977 \ln (1-F)
\end{aligned}
$$

Where $\mathrm{F}$ is the ratio of $\mathrm{q}_{\mathrm{t}}$ and $\mathrm{q}_{\mathrm{e}}$ and $\mathrm{B}_{\mathrm{T}}$ is a constant (Fig. 10d), showing that both film diffusion and intraparticle diffusion are involved in the mechanism.

\begin{tabular}{|c|c|c|c|c|}
\hline Kinetic models & $\begin{array}{c}\text { Rate } \\
\text { constant } \\
\left(\mathrm{K}_{1} \text { and } \mathrm{K}_{2}\right) \\
\left(\mathrm{g} \mathrm{mg}^{-1} \mathrm{~min}^{-1}\right)\end{array}$ & $q_{e, c a l}\left(m_{g ~ ~ g^{-1}}\right)$ & $\begin{array}{c}\text { qe,exp } \\
\left(\mathrm{mg} \mathrm{g}^{-1}\right)\end{array}$ & $\mathbf{R}^{2}$ \\
\hline Pseudo-first order & 0.033 & 1.00 & 0.27466 & 0.951 \\
\hline Pseudo-second order & 4.49 & 0.28368 & & 0.999 \\
\hline
\end{tabular}

Table 2. Kinetic parameters of Cd(II) ion adsorption on to starch-based AC.

\section{Parameters}


(a)

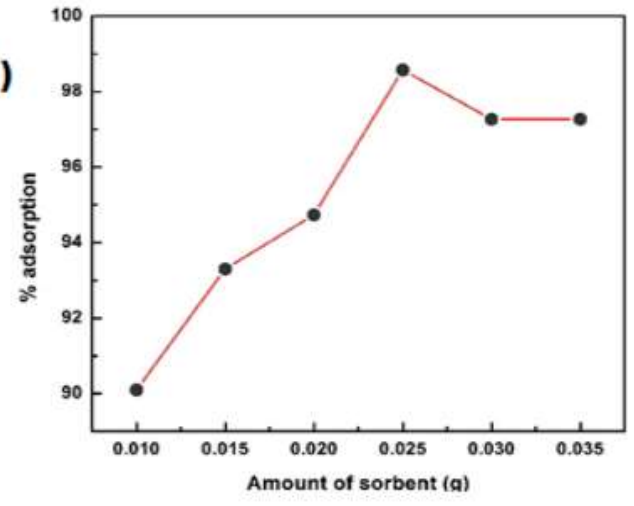

(c)

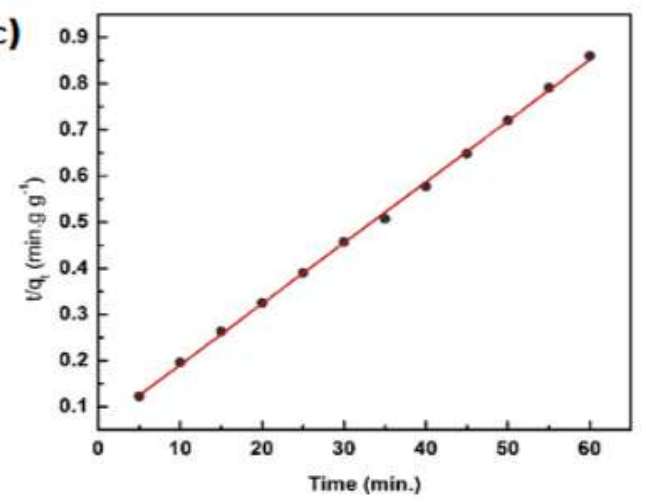

(b)

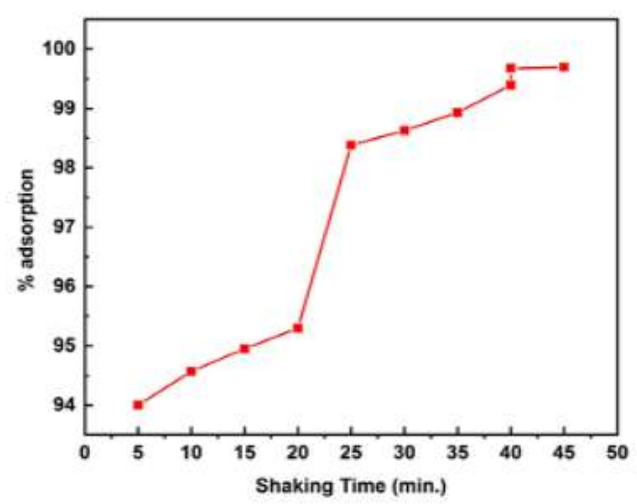

(d)

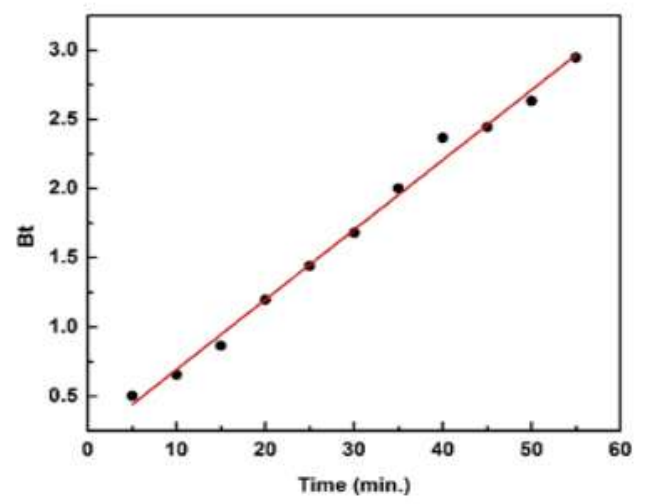

Figure 10. (a) Effect of amount of AC, (b) effect of shaking time, (c) Pseudo $2^{\text {nd }}$ order kinetic and (d) Reichenberg model.

\section{The thermodynamic study}

The effect of temperature on sorption was investigated in the temperature ranges of 283$313 \mathrm{~K}$. It was observed that the adsorption increased with the increases in temperature Figure 6e, which reveals that the process may be chemisorption reverse may be true for physiosorption. This increase in the rate of adsorption with temperature may be due to the efficient flow of sorbate molecules against the concentration gradient or transport of sorbate through the energy barrier. This may also create some new sites on the surface of the sorbent [48]. The thermodynamic parameters like Gibbs free energy change $(\Delta G)$, enthalpy $(\Delta H)$, and entropy $(\Delta S)$ were determined by using the relations below [49].

$$
\begin{gathered}
\Delta \mathrm{G}=-\mathrm{RT} \ln \mathrm{k} \\
\ln \mathrm{K}=-\frac{\Delta \mathrm{H}}{\mathrm{RT}}+\frac{\Delta \mathrm{S}}{\mathrm{R}} \\
\Delta G=\Delta H-T \Delta S
\end{gathered}
$$

The calculated value of $\Delta G$ was $-15.75 \mathrm{~kJ} /$ mole, revealing that the adsorption of the $\mathrm{Cd}(\mathrm{II})$ ion on to $\mathrm{AC}$ is feasible and spontaneous [50]. The magnitude of $\Delta H$ was $6.49 \mathrm{~kJ} \mathrm{~mol}^{-1}$, showing that the sorption mechanism is endothermic [51]. The $\Delta S$ as determined from the intercept of the graph of lnk against $1 / \mathrm{T}$ was $55.66 \mathrm{~J} / \mathrm{mol}$. (Figure 11a) reflecting the sorbate/sorbent complex stability[52]. The thermodynamic results are summarized in Table 3. 
Table 3. Thermodynamic parameters of adsorption of $\mathrm{Cd}(\mathrm{II})$ ion onto AC.

\begin{tabular}{|c|c|c|c|}
\hline Temperature(K) & $\Delta G^{0}\left(\mathrm{~kJ} \mathrm{~mol}^{-1}\right)$ & $\Delta H^{\circ}\left(\mathrm{kJ} \mathrm{mol}^{-1}\right)$ & $\Delta S^{0}\left(J \mathrm{~mol}^{-1} \mathrm{~K}^{-1}\right)$ \\
\hline 283 & -15.75 & \multirow{4}{*}{6.49} & \multirow{4}{*}{55.66} \\
\hline 293 & -16.30 & & \\
\hline 303 & -16.86 & & \\
\hline 313 & -17.42 & & \\
\hline
\end{tabular}
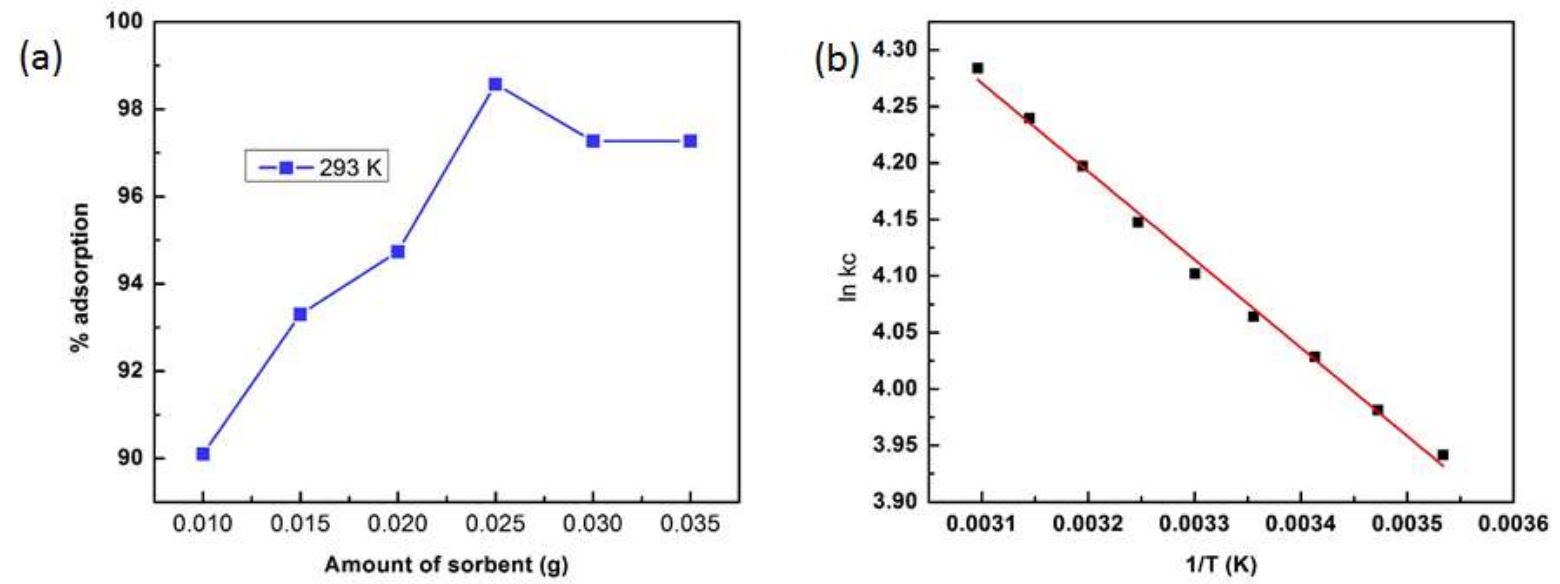

Figure 11. (a) Effect of amount of sorbent, and (b) Determination of thermodynamic parameters by the Van't Hoff equation.

\section{DFT study}

To gain deeper insights into the interactions of $\mathrm{Cd}$ (II) ion with the activated carbon, density functional theory (DFT) simulations are performed which are recently frequently utilized combine with experimental studies to understand the mechanism of adsorption process $[32,53,54]$. The DFT simulations were performed by DMol3 code $[55,56]$, using the spin unrestricted density functional theory along with Perdew Burke Ernzerhof (PBE) in combination with double numerical basis set involving polarization functions (DNP). The Hirschfeld charge density method was used for the population analysis. The adsorption energies were calculated using the formula;

$$
E_{a d}=E_{\text {complex }}-\left(E_{A C}+E_{C d(I I)}\right)
$$

where, $E_{\text {complex }}$ is the total electronic energy of complex system (Cd(II) ion adsorbed over activated carbon), $\mathrm{E}_{\mathrm{AC}}$ and $\mathrm{E}_{\mathrm{Cd}(\mathrm{II})}$ are the energies of activated carbon and $\mathrm{Cd}(\mathrm{II})$ ion separately.

The optimized geometries are represented in Figure 12 and values of adsorption energies, intermolecular distances and charge transfer are collected in Table 4. Four different adsorption modes of $\mathrm{Cd}(\mathrm{II})$ ion onto activated carbon (AC) are simulated which are named as CMP-1, CMP2, CMP-3 and CMP-4 as illustrated in Figure 12. In CMP-1 the Cd(II) ion interacted with the $\mathrm{O}$ atom of $\mathrm{C}=\mathrm{O}$ bond present on the surface of $\mathrm{AC}$. The geometry optimization reveals that the $\mathrm{Cd}(\mathrm{II})$ ion formed in intermolecular bond of bond distance of $2.39 \AA$, while the adsorption energy 
( $\left.E_{\text {ad }}\right)$ shows that the $E_{\text {ad }}$ value for this complex is $-9.20 \mathrm{eV}$, which shows the stronger interaction. The Hirshfeld charge analysis depicts that there is larger charge transfer $(0.59 \mathrm{e})$ occurred from the $\mathrm{Cd}$ (II) ion to the $\mathrm{O}$ atom of the surface which resulted stronger intermolecular bond. In CMP-2 the $\mathrm{Cd}$ (II) ion interacted with the $\mathrm{O}$ atoms of the $\mathrm{NO} 2$ group and $\mathrm{O}$ atom of $\mathrm{C}=\mathrm{O}$ group at the edge of the AC. The optimization shows that the $\mathrm{Cd}$ (II) ion formed intermolecular bonds with one $\mathrm{O}$ atom of $\mathrm{NO} 2$ group and with $\mathrm{O}$ atom of $\mathrm{C}=\mathrm{O}$ group. The bond distances noticed for this interaction is 2.25 and $2.41 \AA$, respectively. The Ead energy and Hisrhfeld charge transfer value obtained for this complex is $-10.03 \mathrm{eV}$ and $0.70 \mathrm{e}$. This larger Ead value and higher charger transfer value demonstrate that the formation of this complex is highly thermodynamically stable. In CMP-3 the $\mathrm{Cd}$ (II) ion interacted with the $\mathrm{SO} 3 \mathrm{H}$ group at the edge of $\mathrm{AC}$. The intermolecular bond distances values calculated for this complex are 2.98 and $2.92 \AA$, respectively. The $E_{\text {ad }}$ and charge transfer values noticed for this complex is $-9.54 \mathrm{eV}$ and $0.59 \mathrm{e}$. While in CMP-4 the $\mathrm{Cd}$ (II) ion placed over the top of hexagonal ring of the AC. The geometry optimization reveals that the $\mathrm{Cd}(\mathrm{II})$ ion form weak intermolecular bonds in this complex having binding distances upto $3.45 \AA$. Smaller $E_{\mathrm{ad}}$ and charge transfer values obtained for this complex which is $-0.45 \mathrm{eV}$ and $0.23 \mathrm{e}$. In summary, the DFT simulations shows that the AC has higher affinity for the adsorption of Cd(II) ions due to the presence of higher negative active sites i.e. N, O and S atom. The Cd formed stronger bonds with these active sites which resulted stronger adsorption. The larger negative values depicts that the adsorption process is spontaneous and thermodynamically stable.
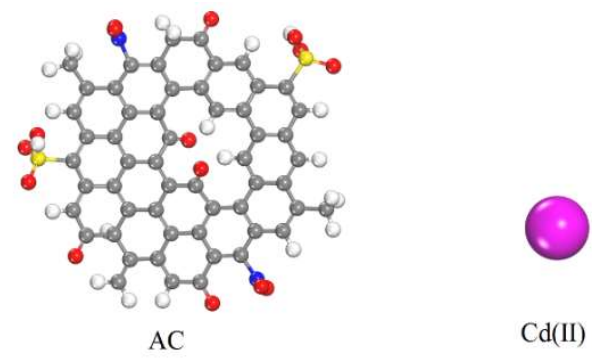

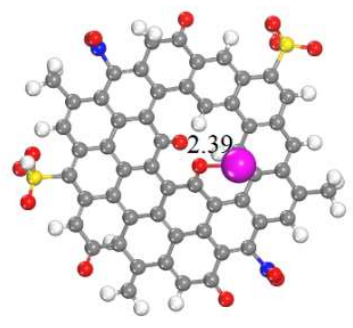

CMP-1

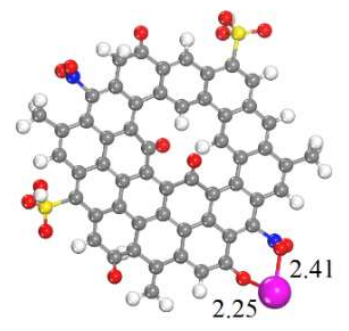

CMP-2

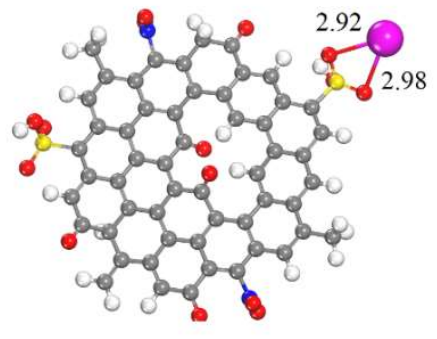

CMP-3

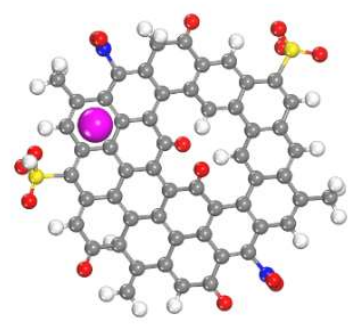

CMP-4

$\bigcirc \mathrm{H} \odot \mathrm{C} \odot \mathrm{OOS}$

Figure 12. Graphical representation of optimized geometry of $\mathrm{AC}$ and $\mathrm{Cd}(\mathrm{II}) @ \mathrm{AC}$ complexes. Bond distance are in $\AA$ 
Table 4. Computed bond distance $(\AA)$, adsorption energy $\left(E_{\mathrm{ad}} \mathrm{eV}\right)$ and Hirshfeld charge transfer $\left(\Delta \mathrm{Q}_{\mathrm{CT}} \mathrm{e}\right)$

\begin{tabular}{|l|l|l|l|l|}
\hline Complex & & Bond distance & $E_{\mathrm{ad}}$ & $\Delta Q_{\mathrm{CT}}$ \\
\hline CMP-1 & 2.39 & -9.21 & 0.59 \\
\hline CMP-2 & & $2.24,2.41$ & -10.03 & 0.70 \\
\hline CMP-3 & $2.92,2.98$ & -9.55 & 0.59 \\
\hline CMP-4 & & $3.45,3.41,3.39$ & -0.45 & 0.23 \\
\hline
\end{tabular}

\section{Conclusions}

The $\mathrm{Cd}^{2+}$ was adsorbed onto activated carbon and the experimental data were adjusted to the Langmuir isotherm. Temperature and $\mathrm{pH}$ of the solutions were shown to influence significantly the adsorption isotherm. At initial $\mathrm{pH}$ of 2 or lower. $\mathrm{Cd}^{2+}$ did not adsorb to the activated carbon. However at $\mathrm{pH}$ greater than $3 \mathrm{Cd}^{2+}$ began to adsorb achieving its maximum adsorption capacity at an initial $\mathrm{pH}$ of 6 .

Based on results obtained it can be (concluded, confirmed, stated) that starch-based activated carbon can be used as an efficient and economical sorbent for the sequestration of $\mathrm{Cd}(\mathrm{II})$ from wastewater. The adsorption phenomena were dependent upon several factors including $\mathrm{pH}$ and the optimum $\mathrm{pH}$ for maximum sorption was found to be 6.0 . The adsorption results obey Langmuir, Freundlich isotherms well. The adsorption capacity and other parameters have been computed from different isotherm constants. The pseudo $2^{\text {nd }}$ order adequately describes the kinetic data. The pseudo $2^{\text {nd }}$ order kinetics shows a high kinetics correlation with experimental data. Moreover, the DFT study shows that the AC has stronger affinity for the adsorption of $\mathrm{Cd}(\mathrm{II})$ ions due to presence of highly active sites. The shorter bond distances in CMP-1, CMP-2 and CMP-2 evince that the Cd(II) strongly interacted with various active sites of the $\mathrm{AC}$, which resulted stronger adsorption.

Therefore, the $E_{\text {ad }}$ values are highly negative which ranges from $-0.45 \mathrm{eV}$ to $-10.03 \mathrm{eV}$, indicates that the adsorption process is spontaneous and thermodynamically feasible. The larger charge transfer $(0.23$ e to 0.70 e) give roots to the presence of stronger intermolecular bond between the $\mathrm{Cd}$ (II) ions and $\mathrm{AC}$.

\section{Author Contributions:}

\section{Funding:}

Data Availability Statement:

\section{Conflicts of Interest:}




\section{Reference}

[1] Z. Ali, R. Ahmad, A. Khan, RSC advances 4 (2014) 50056.

[2] S.M. Hasany, R. Ahmad, J. Environ. Manage. 81 (2006) 286.

[3] C. Peña-Guzmán, S. Ulloa-Sánchez, K. Mora, R. Helena-Bustos, E. Lopez-Barrera, J. Alvarez, M. Rodriguez-Pinzón, J. Environ. Manage. 237 (2019) 408.

[4] C. Teodosiu, A.-F. Gilca, G. Barjoveanu, S. Fiore, Journal of cleaner production 197 (2018) 1210 .

[5] X. Wen, P. Wu, K. Xu, J. Wang, X. Hou, Microchem. J. 91 (2009) 193.

[6] J. Godt, F. Scheidig, C. Grosse-Siestrup, V. Esche, P. Brandenburg, A. Reich, D.A. Groneberg, Journal of occupational medicine and toxicology 1 (2006) 1.

[7] A.C. Davis, P. Wu, X. Zhang, X. Hou, B.T. Jones, Applied Spectroscopy Reviews 41 (2006) 35.

[8] X. Wen, Q. Yang, Z. Yan, Q. Deng, Microchem. J. 97 (2011) 249.

[9] M.P. Waalkes, S. Rehm, C.W. Riggs, R.M. Bare, D.E. Devor, L.A. Poirier, M.L. Wenk, J.R. Henneman, M.S. Balaschak, Cancer Res. 48 (1988) 4656.

[10] K. Seidal, N. Jörgensen, C.-G. Elinder, B. Sjögren, M. Vahter, Scand. J. Work Environ. Health (1993) 429.

[11] H. Li, P. Gao, J. Cui, F. Zhang, F. Wang, J. Cheng, Environmental Science and Pollution Research 25 (2018) 20743.

[12] S. Gunatilake, Methods 1 (2015) 14.

[13] T.A. Kurniawan, G.Y. Chan, W.-H. Lo, S. Babel, Chem. Eng. J. 118 (2006) 83.

[14] A.B. Fuertes, P. Valle-Vigón, M. Sevilla, Chem. Commun. 48 (2012) 6124.

[15] K.-H. Lo, C.-W. Lu, W.-H. Lin, C.-C. Chien, S.-C. Chen, C.-M. Kao, Chemosphere 238 (2020) 124596.

[16] K.-T. Chung, Mutation Research/Reviews in Genetic Toxicology 114 (1983) 269.

[17] M.K. Uddin, Chem. Eng. J. 308 (2017) 438.

[18] A. Ayangbenro, O. Babalola, Int. J. Env. Res. Public Health 14 (2017) 94.

[19] A.A. Khan, M.D. Esrafili, A. Ahmad, E. Hull, R. Ahmad, S.U. Jan, I. Ahmad, J. Mol. Model. 25 (2019) 189.

[20] N. Allen, C. Dai, Y. Hu, J.D. Kubicki, N. Kabengi, ACS Earth and Space Chemistry 3 (2019) 432 .

[21] N. Acelas, E. Flórez, Density functional theory studies of the adsorption of Cr (VI) on Fe-(hydr) oxide: Gibbs free energies and pH effect, Journal of Physics: Conference Series. IOP Publishing, 2019, p. 012051.

[22] R.T. Yang, Adsorbents: fundamentals and applications, John Wiley \& Sons, 2003.

[23] J. Tayone, International Journal of Sciences: Basic and Applied Researchm 19 (2015) 426.

[24] M.T. Shirazani, H. Bakhshi, A. Rashidi, M. Taghizadeh, Journal of Environmental Chemical Engineering 8 (2020) 103910.

[25] K. Yang, T. Pan, Q. Zhao, C. Chen, X. Zhu, P. Wang, B. Chen, Carbon 168 (2020) 254.

[26] A. Tyagi, S. Banerjee, S. Singh, K.K. Kar, International Journal of Hydrogen Energy 45 (2020) 16930.

[27] G. Singh, S. Dwivedi, Environmental Technology \& Innovation (2020) 100751.

[28] S.A. Karim, H.Y. Al-Gubury, N.A. Alrazzak, The Synthesis of a Novel Azo Dyes and Study of Photocatalytic Degradation, Journal of Physics: Conference Series. IOP Publishing, 2019, p. 052054. 
[29] M. Banerjee, R.K. Basu, S.K. Das, Environmental Science and Pollution Research 26 (2019) 11542.

[30] B. Maleki, O. Reiser, E. Esmaeilnezhad, H.J. Choi, Polyhedron 162 (2019) 129.

[31] F. Li, A. Ahmad, L. Xie, G. Sun, Q. Kong, F. Su, Y. Ma, Y. Chao, X. Guo, X. Wei, Electrochim. Acta 318 (2019) 151.

[32] S.U. Jan, A. Ahmad, A.A. Khan, S. Melhi, I. Ahmad, G. Sun, C.-M. Chen, R. Ahmad, Environmental Science and Pollution Research 28 (2021) 10234.

[33] M. Rafatullah, S. Ismail, A. Ahmad, Water 11 (2019) 1304.

[34] M. Naushad, A.A. Alqadami, Z.A. AlOthman, I.H. Alsohaimi, M.S. Algamdi, A.M. Aldawsari, Journal of Molecular Liquids 293 (2019) 111442.

[35] S. Cheng, L. Zhang, A. Ma, H. Xia, J. Peng, C. Li, J. Shu, Journal of Environmental Sciences 65 (2018) 92.

[36] S. Khandaker, Y. Toyohara, G.C. Saha, M.R. Awual, T. Kuba, Journal of Water Process Engineering 33 (2020) 101055.

[37] G. Sharma, M. Naushad, J. Mol. Liq. (2020) 113025.

[38] B.E. Reed, M.R. Matsumoto, Sep. Sci. Technol. 28 (1993) 2179.

[39] T.S. Kazeem, M. Zubair, M. Daud, N.D. Mu'azu, M.A. Al-Harthi, Korean J. Chem. Eng. 36 (2019) 1057.

[40] D.-W. Kim, J.-H. Wee, C.-M. Yang, K.S. Yang, Chemical Engineering Journal 392 (2020) 123768.

[41] M.B. Desta, Journal of thermodynamics 2013 (2013).

[42] J. Zhang, J. Shao, Q. Jin, Z. Li, X. Zhang, Y. Chen, S. Zhang, H. Chen, Fuel 252 (2019) 101.

[43] F. Fajarwati, M. Anugrahwati, I. Yanti, R. Safitri, E. Yuanita, Adsorption Study of Methylene Blue and Eriochrome Black T Dyes on Activated Carbon and Magnetic Carbon Composite, IOP Conference Series: Materials Science and Engineering. IOP Publishing, 2019, p. 012025.

[44] A.M. Alkherraz, A.K. Ali, K.M. Elsherif, Chemistry International 6 (2020) 11.

[45] H. Yuh-Shan, Scientometrics 59 (2004) 171.

[46] Y.-S. Ho, G. McKay, Water research 34 (2000) 735.

[47] S.M. de Oliveira Brito, J.L.C. Cordeiro, L. da Cunha Ramalho, J.F.R. Oliveira, SN Applied Sciences 1 (2019) 1226.

[48] R. Ahmad, M.M. Saeed, A. Ali, J.H. Zaidi, Radiochimica Acta 95 (2007) 451.

[49] Z. Ali, R. Ahmad, A. Khan, B. Adalat, Materials Research Express 5 (2018) 075007.

[50] Y. Chang, J.-Y. Lai, D.-J. Lee, Bioresour. Technol. 222 (2016) 513.

[51] H. Kim, H.J. Cho, S. Narayanan, S. Yang, H. Furukawa, S. Schiffres, X. Li, Y.-B. Zhang, J. Jiang, O.M. Yaghi, Scientific reports 6 (2016) 19097.

[52] M. Peydayesh, S. Bolisetty, T. Mohammadi, R. Mezzenga, Langmuir 35 (2019) 4161.

[53] Z.A. Ghazi, A.M. Khattak, R. Iqbal, R. Ahmad, A.A. Khan, M. Usman, F. Nawaz, W. Ali, Z. Felegari, S.U. Jan, New J. Chem. 42 (2018) 10234.

[54] M. Hussain, N. Khaliq, A. Nisar, M. Khan, S. Karim, A.A. Khan, X. Yi, M. Maqbool, G. Ali, Nanotechnology 31 (2020) 505501.

[55] B. Delley, The Journal of chemical physics 92 (1990) 508.

[56] B. Delley, The Journal of chemical physics 113 (2000) 7756. 
